\title{
Symbolic forms can be mnemonics for recall
}

\author{
CHANG HONG LIU and JOHN M. KENNEDY \\ University of Toronto, Scarborough, Ontario, Canada
}

\begin{abstract}
Form symbolism using squares and circles can aid recall. In Experiment 1 , subjects saw 20 words, each presented in a circle or a square. Words like SOFT and MOTHER were presented in circles in the "congruent" condition, whereas the same words were presented in squares in the "incongruent" condition. Two experiments revealed that words in the congruent condition were more likely to be recalled. A comparison of the conditions with a baseline condition, in which 20 listed words were not closely related to either of the shapes, suggests that the effect was more likely due to facilitation produced by the congruent condition than to inhibition from the incongruent condition.
\end{abstract}

Here we will study whether symbolic visual forms can influence memory. We use the phrase form symbolism for connections between simple forms, such as a circle or a square, and quite abstract referents. As a symbol, a circle can be paired with referents such as "unending" or "soft." Similarly, a square may be linked with "stable" or "hard." In this connection, some authors have used the terms nonverbal metaphor (Hausman, 1989) and physiognomic perception (Lindauer, 1991). However, to call a symbol a metaphor is to suggest that metaphor is the basis for symbolism certainly a controversial claim. Also, the term physiognomic perception suggests that symbols are based on expression (facial expression, in particular, if the term physiognomy is taken literally), which may be too restrictive. We will choose the less theoryladen term form symbolism. A circle, for example, can readily symbolize the "universe" or "contentment." As an illustration, Irving Berlin classified songs into "round" songs and "square" songs, to distinguish ones that were what he termed "natural" from ones he deemed "forced effects," respectively (Bergreen, 1990, p. 386).

Several studies on form symbolism have focused on linear forms. They have shown that people often match words like QUIET and SERENE with a horizontal line rather than with a crooked line (Kreitler \& Kreitler, 1972; Leijonhielm, 1967; Schlesinger, 1980; Wallach \& Kogan, 1965; Werner \& Kaplan, 1963; Winner, 1982). Liu and Kennedy (1993) inquired about the role of symbolism in cognitive tasks. We described a "matching" experiment, and we showed that symbolic relations between words and shapes affect one kind of recall performance. Here we report two new experiments on recall.

In Liu and Kennedy's (1993) matching experiment, the task was to match 20 word pairs (e.g., MOTHER and FATHER) with two geometric shapes (a circle and a

We would like to thank C. M. Macleod and B. Challis for their comments on an early version of this paper. Correspondence should be addressed to C. H. Liu or J. M. Kennedy, Department of Psychology, University of Toronto, Scarborough, ON, Canada M1C 1 A4. square). The word pairs used in the Experiment and the levels of agreement found are shown in Table 1, with the word matched with "circle" on the left of each pair. Agreement ranged from $100 \%$ (SOFT-HARD) to chance ( $51 \%$ On DEEP-SHALLOW).

In Liu and Kennedy's (1993) study, the 20 word pairs from the matching experiment were presented for $5 \mathrm{sec}$ each to two groups of subjects. One word from the pair was presented in a circle, the other in a square. The subjects were asked to remember which word was presented in which figure. One group of participants was the "congruent group." For that group, the words were presented in the shapes in accordance with the consensus in the matching experiment. The other group, with the reverse pairing, was called the "incongruent group." For example, in the congruent condition, SOFT and MOTHER were presented in the circle, whereas HARD and FATHER were presented in the square, and vice versa for the incongruent group.

In the test session, the subjects in both groups were given the pairs of words and the two shapes. They were asked to identify which words went with what shapes. The congruent group recalled $81.8 \%$ of the word-shape associations, but the incongruent group recalled only $64.5 \%$ a reliable $17 \%$ difference. Furthermore, the 10 higher agreement pairs of words were recalled significantly better $(87.2 \%)$ than the 10 lower agreement pairs $(76.3 \%)$ by the congruent group, but not by the incongruent group, which recalled $62.8 \%$ and $66.1 \%$, respectively.

Liu and Kennedy's (1993) experiment is open to a reasonable objection. The congruent group might not have remembered the position of the words in the shapes. They may have studied the pairs of words and realized that some of them could be paired aptly with a circle, and some with a square. This rule could have been used to their advantage on the identification part of the experiment. However, if this was what happened, the identification data should be highly correlated with the consensus data. (Indeed, a simple replication of the matching experiment showed $r=.88, p<.0001$.) In fact, there was only a nonsignificant correlation between the con- 
Table 1

Percent Agreement of Words With Shapes, Derived From Matchings in Liu and Kennedy (1993)

\begin{tabular}{llr}
\hline Circle & Square & Agreement \\
\hline SOFT & HARD & 100 \\
HAPPY & SAD & 94 \\
MOTHER & FATHER & 94 \\
LOVE & HATE & 89 \\
GOOD & EVIL & 89 \\
BRIGHT & DARK & 87 \\
ALIVE & DEAD & 87 \\
LIGHT & HEAVY & 85 \\
SUMMER & WINTER & 81 \\
WARM & COLD & 81 \\
FAST & SLOW & 79 \\
WEAK & STRONG & 79 \\
SPRING & FALL & 74 \\
CAT & DOG & 74 \\
QUIET & LOUD & 62 \\
WALKING & STANDING & 62 \\
EVEN & ODD & 57 \\
ANIMAL & PLANT & 53 \\
FAR & NEAR & 53 \\
DEEP & SHALLOW & 51 \\
\hline
\end{tabular}

Note-The values in the table represent the percentage of occasions that the first word of each pair was matched with the circle and the second word of the pair was matched with the square.

gruent group's recall scores and the percentage of agreement in the consensus group ( $r=.34, p<.13)$. It is likely, then, that the congruent group had an advantage over the incongruent group.

Here we attempt to support this interpretation in two experiments. In Experiment 1 we used a more challenging task; subjects were to freely recall the words from Liu and Kennedy's (1993) list and identify them with the shapes in which they originally appeared. In Experiment 2 we compared a modified list of words, in which the symbolic relations between the words and shapes were strengthened, with a baseline condition, in which the words were not closely related to either shape.

\section{EXPERIMENT 1}

Liu and Kennedy (1993) gave subjects the list of words and asked them to recall the shapes in which they had been presented. Consider a task involving stricter demands. Subjects can be asked to recall the words from the study list, as well as to identify the shapes with which the words were paired, not just to pair shapes with a list of words given by the experimenter. Symbolic relations may facilitate memory in this task by organizing the material into chunks. Categorical relations aid in chunking material (Bower, Clark, Lesgold, \& Winzenz, 1969; Mandler, 1967), and some (Ortony, 1975) contend that metaphors have the same function. When words are appropriately paired with the two shapes, the subjects could spontaneously organize the words into two apt clusters - the "circle" word cluster and the "square" word cluster-and produce superior recall.

\section{Method}

Subjects. Sixty subjects from an introductory psychology course at the University of Toronto were randomly assigned to a congruent group and an incongruent group, with 30 subjects each.

Stimuli. A $45-\mathrm{mm}$-diam. circle and a $40-\mathrm{mm}$ square were drawn with white outlines, $0.5 \mathrm{~mm}$ wide, on a black background of a computer screen. The list of 20 words, drawn largely from Liu and Kennedy (1993), is shown in Table 1. We chose only one word from each pair because, in free recall, successfully recalling one word of a pair would almost inevitably lead to the recall of the other (i.e., recalling SOFT leads with high probability to the recall of HARD). Among the 20 words, there were 12 high-agreement words (greater than $79 \%$ in Table 1). The 12 high-agreement words were of two kinds: 6 "circie words" and 6 "square words." The circle words were SOFT, MOTHER, SUMMER, HAPPY, FAST, and ALIVE. The square words were COLD, DARK, HEAVY, STRONG, EVIL, and HATE. The 8 low-agreement words were also divided into circle words and square words, with 4 in each type. The low-agreement circle words were CAT, QUIET, WALKING, and PLANT. The low-agreement square words were ODD, NEAR, SHALLOW, and CLASSIC. Only the word CLASSIC was not drawn from the matching experiment. Pilot testing (with 31 subjects) indicated low levels of agreement $(58 \%)$ on assigning circle and square to the pair MODERN and CLASSIC. CLASSIC replaced SPRING, which was not used since it would be too easily guessed from the word SUMMER in the present list. All the lowagreement words are below $74 \%$ in Table 1 . The letter size was $6 \mathrm{~mm}$, in white, on the black background of the computer screen.

Procedure. Both groups were given the same procedures, except that the circle words in Table 1 were presented in the circle and the square words were presented in the square to the congruent group, and vice versa for the incongruent group.

The subjects were tested individually. Instructions were given on the computer screen and were also read aloud by the experimenter. The first part of the experiment was the study session. The subjects were presented with the list of words, one word at a time. Each word was presented either in the circle or in the square. Each presentation started with a 2 -sec blank screen, which was followed by a warning sound that lasted for $200 \mathrm{msec}$. The warning sound was to call the subjects' attention to the coming presentation. Two hundred milliseconds after the warning sound, a shape was displayed on the center of the screen and a word was displayed on the center of the shape for $3.5 \mathrm{sec}$. This was repeated until the end of the list. The high-agreement words were always presented between Positions 5 and 16 in the serial order in the study list. This was to avoid ceiling effects arising from high-agreement words gaining from primacy and recency effects. The order of the 12 high-agreement words was randomized for each subject. The lowagreement words were always presented either in the first four positions $(1-4)$ or in the last four positions $(17-20)$.

The test session immediately followed the study session. The subjects were given a data sheet containing 10 circles and 10 squares and were asked to try to recall the words from the study list and to write the words in the shapes in which the words had been presented. If they reported that they could not recall any more before completing the full list of 20 , they were asked to make their best guess for the rest of the words until 20 words had been reported. Most of the subjects took 2-4 min to complete what they could remember first, and spent a much longer time $(5-10 \mathrm{~min})$ completing the rest after they were told to do so. Only 1 subject-a member of the congruent group-did not have to be told to continue until completing all 20 words, because she could remember all the words in her first attempt.

\section{Results}

Table 2 shows "total recall" scores - that is, the number of words correctly recalled whether or not they were recalled in the correct shapes. Mean total recall for the congruent group was $9.0 \%$ higher than mean total recall for the incongruent group $[t(58)=2.55, p<.01]$, and mean recall of the high-agreement words by the congruent group was $12.7 \%$ higher $[t(58)=2.81, p<.01]$. The 
Table 2

Percent Correct Recall (With Standard Deviations, $S D$ ) of Studied Words as a Function of Shape Congruency at Study

\begin{tabular}{|c|c|c|c|c|c|}
\hline & \multicolumn{4}{|c|}{ Group } & \multirow[b]{3}{*}{ Difference } \\
\hline & \multicolumn{2}{|c|}{ Congruent } & \multicolumn{2}{|c|}{ Incongruent } & \\
\hline & $\begin{array}{c}\text { Percent } \\
\text { Recall } \\
\end{array}$ & $S D$ & $\begin{array}{c}\text { Percent } \\
\text { Recall }\end{array}$ & $S D$ & \\
\hline Whole list ( 20 items) & 60.2 & 12.5 & 51.2 & 14.7 & $9.0^{*}$ \\
\hline High agreement ( 12 items) & 63.3 & 17.7 & 50.6 & 17.4 & $12.7^{*}$ \\
\hline Low agreement ( 8 items) & 55.4 & 19.3 & 52.1 & 20.0 & 3.3 \\
\hline
\end{tabular}

${ }^{*} p<.01$

mean recall of the low-agreement words differed by a nonsignificant $3.3 \%[t(58)=0.66, p>.5]$.

Consider now the words recalled but "misplaced"that is, recalled in connection with the wrong shape. The mean percentage of misplaced words was $1.9 \%$ for the congruent group and $8.0 \%$ for the incongruent group $[t(38)=-3.67, p<.001]$. The mean percentage of misplaced high-agreement words was $2.8 \%$ for the congruent group and $8.6 \%$ for the incongruent group-again a reliable difference $[t(44)=-2.7197, p<.01]$. The mean percentage of misplaced low-agreement words was $0.4 \%$ for the congruent group and $7.9 \%$ for the incongruent group, which was also reliably different $[t(32)=$ $-3.96, p<.001]$.

The words reported after the subject indicated being unable to recall more words can be called "additional guesses." The mean percentage of correct additional guesses for the congruent group was $1.2 \%$, and for the incongruent group was $2.4 \%$ (n.s.).

\section{Discussion}

The congruent group recalled more words from the study list and associated them correctly with the forms more often. This effect is carried largely by the high-agreement words. Some of the subjects in the congruent group reported that they found some of the words in the study session to be meaningfully related to the circle and others to the square.

\section{EXPERIMENT 2}

It is not easy to tell whether the difference between the congruent and incongruent group in Experiment 1 was due to facilitation produced by the congruent condition, inhibition produced by the incongruent condition, or both. We solved this problem in Experiment 2 by adding a baseline condition, in which most of the words were close to randomly related to the shapes.

Since the effect in Experiment 1 was likely carried by high-agreement words, the size of the effect of the whole list in Experiment 1 could be magnified by replacing the low-agreement words in the study list with high-agreement words. Also, since the effect in Experiment 1 was relatively small $(9 \%)$, it is worth showing that the effect can be replicated.

\section{Method}

Subjects. Subjects from undergraduate courses at the University of Toronto were randomly assigned to the three groups-a congruent group, an incongruent group, and a baseline group-with 17 subjects in each group.

Stimuli. The list of $\mathbf{2 0}$ words for the congruent and incongruent groups was drawn from the high-agreement words in Experiment 1, plus new words, including 6 high-agreement words. The 6 high-agreement words replaced the low-agreement words in Experiment 1 . The circle word CAT, which had a relatively high level of agreement $(74 \%)$ in Table 1, was retained. The 6 new high-agreement words were 3 circle words (BEAUTY, LIQUID, and WATER) and 3 square words (BITTER, HARSH, and PART). These words were drawn from a pilot study (with 31 subjects). In the pilot study, subjects assigned the shapes to these words with a consensus higher than $71 \%$. In addition, a square word (LOUD, with an agreement level of $62 \%$ in Table 1) was added to the list, to incorporate a further change. Thus, 19 of the 20 words had a high agreement level. The list of 20 words for the baseline group was drawn from the 7 low-agreement words in Experiment 1 plus 13 low-agreement words drawn from the pilot study. The new low-agreement words were RED, COME, BROKEN, COWARD, DEFENSE, INCLUSIVE, PLAYING, PHILOSOPHY, BORING, BRAVE, LOW, OLD, and SCIENCE. These words were all below $65 \%$ agreement in the pilot test. The other aspects of the stimuli were the same as those in Experiment 1.

Procedure. Three groups followed the procedures used in Experiment 1 , except that all the word lists were completely randomized.

\section{Results}

The mean total recall scores were $65.0 \%(S D=8.8)$ for the congruent group, $53.8 \%(S D=10.8)$ for the incongruent group, and $48.8 \%(S D=13.6)$ for the baseline group. An analysis of variance (ANOVA) showed a main effect $[F(2)=9.17, p<.0004]$. A contrast analysis of the means showed significant differences between the congruent and incongruent groups $[F=8.35, p<.006]$, and between the congruent and baseline groups $(F=17.49$, $p<.0001)$. The difference between the incongruent and baseline groups was nonsignificant $(F=1.67, p>.2)$.

The mean percentage of misplaced words was $2.9 \%$ $(S D=4.3)$ for the congruent group, $6.1 \%(S D=6.5)$ for the incongruent group, and $4.7 \%(S D=5.1)$ for the baseline group. An ANOVA did not show a significant main effect $[F(2)=1.53, p>$.2].

The mean percentage of correct additional guesses, after the subjects reported being unable to recall additional words, was $3.2 \%(S D=3.5)$ for the congruent group, $4.1 \%(S D=3.6)$ for the incongruent group, and $1.7 \%(S D=2.5)$ for the baseline group. The differences were not significant.

\section{Discussion}

More words were recalled by the congruent group than by the incongruent group or the baseline group. When the low-agreement words in Experiment 1's study list were replaced with high-agreement words, the result was a slightly larger difference between the congruent and the incongruent groups (11.2\%) than was observed in Experiment $1(9.0 \%)$. The effect size in Experiment 2 was intermediate between the differences in total recall scores for the whole list $(9.0 \%)$ and the high-agreement words $(12.7 \%)$ in Experiment 1 .

Since the mean total recall in the incongruent group was not lower than that for the baseline group, the effect is more likely due to facilitation from the congruent condition than to inhibition from the incongruent condition.

Although the congruent group misplaced words in shapes less often than the incongruent group, and the incongruent group misplaced the words in shapes more often than the baseline group (and hence the results resemble the findings in Experiment 1), the differences in Experiment 2 were not statistically significant. 


\section{GENERAL DISCUSSION}

The results in both experiments suggest that the congruent groups could use symbolic relations as an organizational scheme to organize the words into memorable clusters or chunks. Our interpretation of the results has parallels in discussions of memory for other kinds of nonliteral meanings. Hayes (1980), Hayes and Tierney (1980), Mayer (1980), and Mayer and Bromage (1980) suggested that analogies can serve as organizers and may even enhance learning and recall. The literature is mixed on the question of enhanced performance. Harris (1979) found no difference in memory for metaphors and nonmetaphors. Bock and Brewer (1976, cited by Ortony, Reynolds, \& Arter, 1978) found no difference in recognition memory for literal and figurative meanings of expressions. However, Tanhauser (1978) found that subjects recognized metaphorical-context targets better than literalcontext targets after $24 \mathrm{~h}$. Also, Mio, Thompson, and Givens (1993) found that allegories or metaphors were more memorable than their literal counterparts. Some of the confusion in the literature may arise from different opinions about what constitutes an apt, literal paraphrase for a nonliteral proposition.

Our results indicate that symbolic relations between shapes and words can aid memory. But the effect is unlikely to depend on some preexisting knowledge, such as known categories (Bower et al., 1969; Mandler, 1967) because subjects are unlikely to possess the symbol-referent pairs such as circle-SUMMER, square-DARK, and so on in their long-term memory preexperimentally. Neither does the organization depend on making arbitrary associations between items on a study list and existing structures of concepts, such as serially ordered concepts like "freshman-sophomore-junior-senior" or "one-two-threefour-five" (Crowder, 1976; DeSoto \& Bosley, 1962; Ebenholtz, 1966 Pollio, 1968; Pollio \& Draper, 1966). Rather, it seems to rely on novel relations between symbols and apt referents.

How are novel symbolic relations formed? Here we can only give a preliminary account. We see forms as serving several functions; they can depict (e.g., pictorial representations), be metaphoric (e.g., motion lines, see Kennedy, 1982; Kennedy, Green, \& Vervaeke, 1993), or be symbolic (e.g., some aspects of abstract thoughts and emotions being represented by a circle). Establishing a symbolic relation between a form and a referent is a matching task in which the signified is fitted to a signifier. The fitting depends upon some crucial features in common to the signifier and the signified. For instance, "infinity" fits with circle because both are "unending." The use of crucial features makes a symbolic relation nonarbitrary (as is demonstrated by the consensus in Liu \& Kennedy, 1993). As Saussure (1966) remarks, "There is the rudiment of a natural bond between the signifier and the signified. The symbol of justice, a pair of scales, could not be replaced by just any other symbol, such as a chariot" (p. 68). If justice's symbol was changed to a chariot, it might be to urge that the execution of justice should be swift, with the risk of being reckless.

Symbolism may be like analogy at times in that it can involve twopart relations. $A$ is to $B$ as $C$ is to $D$; a mother is to a father as a circle is to a square. A symbolic vehicle may be generally understood to be a member of a set, as a circle is understood to be a member of a set of basic Euclidean forms (circle, square, triangle, etc.). When subjects are invited to ascertain which form would be a good symbol for a given referent, they may generally consider the vehicle and the features they select from the vehicle as parts of sets, with alternates. That is, they may consider circle versus square, smooth versus angular, curved versus straight, and so on.

However, symbolism is not identical to analogy. In analogy, the ideas in the target domain are often understood via the source domain. For example, the relation between an electron and a nucleus is often understood through the relation between the earth and the sun. The electron is taken to be a small body circling a larger one, in the solar system analogy. The analogy functions "as an explanation," allowing the observer to appreciate new properties of the target. In contrast, in form symbolism, we are unlikely to understand MOTHER via a circle. It is quite the reverse-our subjects judged that MOTHER can be symbolized by a circle because they already knew a set of relevant features of both MOTHER and circle. The symbol draws attention to some of the prop- erties the subjects already knew were present, to emphasize or highlight features.

There is yet another respect in which symbols are unlike analogies. Curiously, a symbol is often difficult to justify when it is explained succinctly. We have noted that subjects may explain that a circle is soft, symbolically, because "it is round and smooth." But many round, smooth objects are hard (e.g., pebbles on a beach can be worn round and smooth). In contrast, once an analogy's basis is pointed out, it is justified-for example, electrons and the earth both orbit a central, powerful body.

In sum, form symbolism can aid memory, likely via clustering items.

\section{REFERENCES}

BergreEn, L. (1990). As thousands cheer: The life of Irving Berlin. New York: Penguin Books.

BoCK, J. K., \& BREWER, W. F. (1976). Comprehension and memory of the literal and figurative meaning of proverbs. Unpublished manuscript.

Bower, G. H., Clark, M. C., Lesgold, A. M., \& Winzenz, D. (1969). Hierarchical retrieval schemes in recall of categorical word lists. Journal of Verbal Learning \& Verbal Behavior, 8, 323-343.

Crowder, R. G. (1976). Principles of learning and memory. Hillsdale, NJ: Erlbaum.

DeSoto, C. B., \& Bosley, J. J. (1962). The cognitive structure of a social structure. Journal of Abnormal and Social Psychology, 64, 303307

EBENHOLtz, S. M. (1966). Serial-position effect of ordered stimulus dimensions in paired-associate learning. Journal of Experimental Psychology, 71, 132-137.

HaRR1s, R. J. (1979). Memory for metaphors. Journal of Psycholinguistic Research, 8, 61-71.

HAUSMAN, C. R. (1989). Metaphor and art: Interactionism and reference in the verbal and nonverbal art. New York: Cambridge University Press.

HAYES, D. A. (1980, April). Differential effects of analogy on prose learning. Paper presented at the meeting of the American Educational Research Association, Boston.

HAYES, D. A., \& TIERNEY, R. J. (1980). Increasing background knowledge through analogy (Tech. Rep. No. 186). Urbana, IL: University of Illinois, Center for the Study of Reading.

KENNEDY, J. M. (1982). Metaphor in pictures. Perception, 11, 589-605.

Kennedy, J. M., Green, C. D., \& Vervaeke, J. (1993). Metaphoric thought and devices in pictures. Metaphor \& Symbolic Activity, 8, 243-255

Kreitler, H., \& Kreitler, S. (1972). Psychology of the arts. Durham, NC: Duke University Press.

Leijonhielm, C. (1967). Colours, forms and art: Studies in differential aesthetic psychology. Stockholm: Almqvist \& Wiksell.

LiNDAUER, M. S. (1991). Physiognomy and verbal synaesthesia compared: Affective and intersensory descriptors of nouns with drawings and art. Metaphor \& Symbolic Activity, 6, 183-202.

LIU, C. H., \& KENNEDY, J. M. (1993). Symbolic forms and cognition. Psyke \& Logos, 14, 441-456.

Mandler, G. (1967). Organization and memory. In K. W. Spence \& J. T. Spence (Eds.), The psychology of learning and motivation (Vol. 1, pp. 327-372). New York: Academic Press

MAYER, R. E. (1980). Elaboration techniques that increase the meaningfulness of technical text: An experimental test of the learning strategy hypothesis. Journal of Educational Psychology, 72, 770784.

MAYER, R. E., \& Bromage, B. K. (1980). Different recall protocols for technical texts due to advance organizers. Journal of Educational Psychology, 72, 209-225.

Mio, J. S., Thompson, S. C., \& Givens, G. H. (1993). The commons dilemma as metaphor: Memory, influence, and implications for environmental conservation. Metaphor \& Symbolic Activity, 8, 23-42.

OrTONY, A. (1975). Why metaphors are necessary and not just nice. Educational Theory, 25, 45-53. 
Ortony, A., Reynolds, R. E., \& ArTer, J. A. (1978). Metaphor: Theoretical and empirical research. Psychological Bulletin, 85, 919-943.

Pollio, H. R. (1968). Associative structure and verbal behaviour. In T. R. Dixon \& D. L. Horton (Eds.), Verbal behaviour and general behaviour theory (pp. 37-66). Englewood Cliffs, NJ: Prentice-Hall

Pollio, H. R., \& DraPer, D. O. (1966). The effect of a serial cognitive structure on paired-associates learning. Journal of Verbal Learning \& Verbal Behavior, 5, 301-308.

SAussure, F. (1966). Course in general linguistics. New York: McGraw-Hill.

SCHLESINGER, L. B. (1980). Physiognomic perception: Empirical and theoretical perspectives. Genetic Psychology Monographs, 101, 7197.
TANHAuSER, S. L. (1978, May). Levels of interpretation: A study of metaphor-literal differences. Paper presented at the Midwestern Psychological Association, Chicago.

Wallach, M. A., \& Kogan, N. (1965). Modes of thinking in young children. New York: Holt, Rinehart \& Winston.

WERNER, H., \& KAPLAN, E. (1963). Symbol formation: An organismicdevelopmental approach to language and the expression of thought. New York: Wiley.

WINNER, E. (1982). Invented worlds: The psychology of the arts. Cambridge, MA: Harvard University Press.

(Manuscript received April 4, 1994;

revision accepted for publication July 29,1994 .) 